\title{
An alternative approach of Risk Analysis for Multivariable Alarm System
}

\author{
B.M. S. Arifin* and M.A.A. S. Choudhury \\ Department of Chemical Engineering, \\ Bangladesh University of Engineering \& Technology (BUET), Dhaka-1000, Bangladesh
}

\begin{abstract}
Alarm system of a plant works as a safeguard to prevent hazards and unexpected accidents. But too many false alarms may make the operators indifferent to critical alarms that may lead to serious mishaps. In this study, the risk based multivariable alarm system proposed by [1] has been restudied and an alternative approach of quantifying the system failure probability is proposed. Since in all the modern chemical plants there are adequate safety measures and the safety is ensured by installing different instruments, and the failure data of these instruments are available in [2], so the risk of the system can be quantified by applying statistical methods as a combination of several instruments If the risks and hazards associated with a system can be properly identified, the hazards can be correlated with the failure of the different parts of the instrumentation system and the probabilities of failure can be estimated [3]. Then it is necessary to know the consequence factor of a hazardous situation since risk depends on both the failure probability and the consequence probability. According to the severity of failure probabilities of the instruments of the physical system, the alarms can be indexed and all alarms of a single system can be consolidated into a single alarm, which will notify the operator about the importance of the situation. Since risks can also be properly indexed, it is easier for the operator to take necessary steps as soon as he gets the alarm. Thus the purpose of the alarm system will be fully satisfied - to keep the process operation safe and sound. In this study, failure probabilities were calculated for a simple model process namely a tank heating system.
\end{abstract}

Keywords

Risk based alarm system; multivariable alarm system; probability of failure.

\section{Introduction}

A typical Chemical process plant involves several unit operations and unit processes. And these units are interrelated with complex piping systems. So, any fault in one of them can affect the subsequent units and can cause unsatisfactory performance of the plant, even plant shut down and hazardous accidents may occur. So, to meet the demand of higher efficiency, better quality of product, safety of the plant personnel and surroundings process monitoring is of great importance. Moreover stringent environmental regulations have compelled the process industries for improved and sophisticated safety and control strategies.

With the recent drastic advancement of hardware and software it is now easy to get process information from almost all the process variables which in turns have made control system more reliable [4]. However, despite of the availability of improved control strategies and advanced sensors, abnormal process conditions [5] have not yet been eliminated. And hence, operator interventions are still frequently required to manage abnormal situations.

Among all the instruments and sensors required for process safety and control strategy, alarm plays a very important role. The main purposes of alarm are to warn a possible critical condition to seek the attention of an operator and thus to prevent, control and mitigate the effects of an abnormal situation. But on many occasions, alarms have been reported as a contributor to abnormal events [6].

However, a serious problem exists in the industry namely alarm flooding. It is shown in [7] that an average operator takes about 10 minutes to process and respond to an alarm, so the EEMUA Guide [8] suggests that an operator should not receive more than six alarms per hour. However, in reality an operator may receive hundreds and thousands of alarms and most of these alarms are false or nuisance. Too many alarms only distract the operator from operating plant, which may be the cause of the critical alarms being ignored. This means that the alarm system is at its least effectiveness when it is needed the most [8].

The causes of alarm flooding are very clear. Firstly, alarms are installed on the basis of what could be done rather than what should be done. As a result, there are simply too many alarms installed. Secondly, conservative approaches like turning an alarm in case of doubt are also responsible for this undesirable phenomenon. The final and root cause for this situation has been identified as the single variable nature of the alarms [9]. This has resulted in a voluminous increase in the number of alarms causing operator overwhelming during a critical situation [10].

Various approaches for avoiding alarm flooding have been proposed by different authors. Alarm filters are proposed by [4]. There are some guidelines for incorporating risk estimation in the alarm systems [8]; however, not for alarm annunciation. Risk based analysis for safety monitoring based on Baysian network has been proposed in [11]. Application of risk and loss based monitoring have been reported for road and rail tunnel monitoring in [12] and for earthquake early warning systems in [13].

A predictive mechanism is one of the most sought after criterion for a successful alarm system as time is a critical factor during an abnormal event[1]. Use of models for

*Corresponding Author's Email : bmsirajeel@che.buet.ac.bd 
prediction of possible runaway condition in a reactor has been reported in [14]. Models have also been used for disturbance management in [15].

In [1] the authors proposed a risk based alarm design and analysis approach. In that approach, the process variables are grouped to be represented by a number of systems. A single alarm is then assigned for each system instead of individual variables thus reducing the number of alarms. From the measured value of the single variables, the risk associated with individual systems is estimated. Also from the relationships among the variables, future risk associated with each system is evaluated. Finally the overall risk for a particular system is obtained from the current and predicted risk and the overall risk that is determined is compared with a predefined threshold value. Decision regarding alarm activation is taken on the basis of this compared value and the alarm for the most severe variable will be annunciated for the operator to take action. Whereas in the traditional single variable alarm system, alarms for all the variables those are interrelated with the most severe one could be set on simultaneously as they might also have crossed their threshold values as a consequence of the severe one. Thus this may create confusion among the operator as the rest of the variables are not risk prone at all.

But the work of [1] lacks different aspects in details, e.g. how to define the systems, how to identify the hazards, their probabilities and impacts and how to calculate the overall risk. Also details on how to predict future risks is not addressed in the article.

Inspired by [1] the authors of this article has tried to estimate the risk associated with a system by using the failure probability of the instruments used for ensuring the safety of the system rather than measuring the risk associated with the process variables. Because, a process variable can assume different data in different processes depending on the process characteristics though the system is same. Risk associated with a process variable in a faulty process will be higher than that of the same process variable in a sound process. So, if we want to utilize the risk based alarm system in case of a new process whose characteristics are not still identified this alarm system suggested in [1] might not work.

Since, instruments are must in all of the present chemical process plants, so it may be a better approach to predict the risk associated with a system by using the failure probabilities of such instruments. This failure probability data along with the consequence probability factors which will be available from experience, will finally give the estimation of the risk. And this approach does not depend on process characteristics and is applicable for the very new process also.

Again, present authors have tried to define a system for designing multivariable alarm system, where there will be only one alarm for the system instead of an alarm with each variable. The variables that are closely related with each other i.e. change in one variable will affect the other variables within 5-10 minutes can be grouped as a system.
In this article, failure probability of a simple tank heating system was estimated after a detailed hazard analysis.

\section{Description of the System}

A simple tank heating system with water as a working fluid was considered as the system. Saturated steam was used for the heating purpose. In this case, the process variables are - water inlet flow rate, water outlet flow rate, tank level, steam flow rate/pressure, water temperature. These variables will be grouped as our system. Water inlet and outlet flow rates are manipulated to maintain the level of tank, and steam pressure is manipulated to maintain the tank water temperature. Because, the hazards of this simple system are related with these two variables (tank level and tank water temperature).

Three control loops are attached in this system. The higher level control loop is to prevent the overflow of the tank, the lower level control loop is to prevent the dryness of the tank and the water temperature control loop is to prevent overheating and cooling of the tank water. Each of the control loops is consisted of a transmitter, controller and a control valve. Other instruments are ignored to ensure the easiness of calculation. Figure 1 is a schematic diagram of the process.

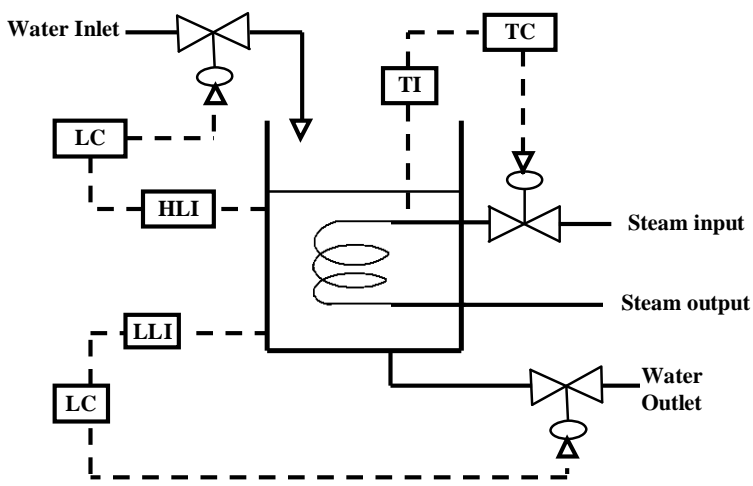

Figure - 1 : Schematic diagram of the system

One might get wonder why there are both higher and lower level control loops. It is because; the higher level control loop will ensure the prevention of overflowing incident. It will make the system isolated from its previous unit in case of emergency. The lower control loop will do the same when level of the tank will be too low.

\section{Methodology}

Individual failure rate for each of the instruments are obtained from literature and using the combination of the different failure rates will give the overall failure rate. Hazard analysis procedure is given below : 


\section{Hazard Analysis}

Equipment failures in a process occur as a result of a complex interaction of the individual components, and overall failure probability depends on the nature of this interaction.

The causes of the four undesirable events of our system are listed below. Here, the undesirable events are correlated with the faults of the control instruments. For easiness of calculation only the major instruments are considered here. I/P and other smaller instruments are omitted in this study. The hazardous situation may arise due to the failure of individual instrument or simultaneous failure of more than one instrument. The overall failure probability is a combination of all such possibilities.

Here, the possible sources of hazards are -

1) Overflow of the tank.

2) Dryness of the tank

3) Overheating of the tank.

4) Cooling of the tank.

5) High temperature with low liquid level may cause the structural damage of the tank [1].

\section{Causes of Tank overflow}

1) High level indicator(HLI) may fail individually

2) Level controller(HLC) may fail individually

3) Inlet water control valve may fail individually

4) Both cause 1 and cause 2 may occur simultaneously

5) Both cause 2 and cause 3 may occur simultaneously

6) Both cause 3 and cause 1 may occur simultaneously

7) All three causes of 1,2 and 3 may occur simultaneously

\section{Causes of Complete Dryness}

1) Low level indicator(LLI) may fail individually

2) Level controller(LLC) may fail individually

3) Outlet water control valve may fail individually

4) Both cause 1 and cause 2 may occur simultaneously

5) Both cause 2 and cause 3 may occur simultaneously

6) Both cause 3 and cause 1 may occur simultaneously

7) All three causes of 1,2 and 3 may occur simultaneously

\section{Causes of Overheating/Cooling}

1) Temperature indicator(TI) may fail individually

2) Temperature controller(TC) may fail individually

3) Steam inlet valve may fail individually

4) Both cause 1 and cause 2 may occur simultaneously

5) Both cause 2 and cause 3 may occur simultaneously

6) Both cause 3 and cause 1 may occur simultaneously
7) All three causes of 1,2 and 3 may occur simultaneously

The Failure rate is listed as faults per year for different process instruments in [2]. Of them our necessary ones are given in Table -1 :

Table -1 : Failure rate of some instruments.

\begin{tabular}{|c|c|}
\hline Instruments & $\begin{array}{c}\text { Faults/year } \\
(\boldsymbol{\mu})\end{array}$ \\
\hline Controller & 0.29 \\
\hline Control Valve & 0.60 \\
\hline $\begin{array}{c}\text { Liquid Level } \\
\text { Measurement }\end{array}$ & 1.70 \\
\hline $\begin{array}{c}\text { Temperature } \\
\text { Measurement }\end{array}$ & 0.52 \\
\hline
\end{tabular}

As the failure rate is now known, the probability that the instrument will not fail during the time interval $(0, t)$ is given by Poisson Distribution [16]

$$
R(t)=e^{-\mu t}
$$

Where, $\mathrm{R}$ is the reliability of the instrument. In this equation the failure rate is considered to be a constant. From this equation, it is seen that as time becomes large, the reliability goes to 0 . The higher will be the failure rate, the lesser time will be required to reach the zero reliability state.

The complement of reliability is the failure probability, $\mathrm{P}$ and it is defined as -

$$
P(t)=1-R(t)=1-e^{-\mu t}
$$

The failure probabilities of the instruments of our system are calculated as in Table -2 . Here, the time interval is taken as 1 year

Table - 2 : Failure probability of the individual instruments.

\begin{tabular}{|c|c|}
\hline Instruments & $\begin{array}{c}\text { Failure } \\
\text { probability }\end{array}$ \\
\hline Controller & 0.252 \\
\hline Control Valve & 0.451 \\
\hline $\begin{array}{c}\text { Liquid Level } \\
\text { Measurement }\end{array}$ & 0.817 \\
\hline $\begin{array}{c}\text { Temperature } \\
\text { Measurement } \\
\text { (Thermocouple ) }\end{array}$ & 0.405 \\
\hline
\end{tabular}

Now probability of each of the causes of Overflow of the tank can be calculated. It is noted that each of these 
causes are mutually exclusive. And failure of Control valve and Controller are independent of each other.

\section{Results and Discussion}

The calculated failure probability of tank overflow and heating are shown in Table -3 and 4

Table - 3 : Failure probability of the causes of Overflow of the tank

\begin{tabular}{|c|c|}
\hline Causes & Failure Probability \\
\hline Cause - 1 & 0.817 \\
\hline Cause - 2 & 0.252 \\
\hline Cause - 3 & 0.451 \\
\hline Cause - 4 & 0.206 \\
\hline Cause - 5 & 0.114 \\
\hline Cause - 6 & 0.368 \\
\hline Cause - 7 & 0.093 \\
\hline Overall & $\mathbf{0 . 9 2 5}$ \\
\hline
\end{tabular}

While calculating the overall failure probability it is to be noted that the hazardous situation of tank overflow can be caused by each of the causes individually and some of the causes may trespass into the boundaries of other causes.

The failure probabilities of the causes of complete dryness of the tank will be similar as Table - 3. Simple probabilistic methods were used to calculate the overall failure probabilities.

Table - 4: Failure probability of the causes of Overheating / Cooling of tank water.

\begin{tabular}{|c|c|}
\hline Causes & Failure Probability \\
\hline Cause - 1 & 0.405 \\
\hline Cause - 2 & 0.252 \\
\hline Cause - 3 & 0.451 \\
\hline Cause - 4 & 0.102 \\
\hline Cause - 5 & 0.114 \\
\hline Cause - 6 & 0.183 \\
\hline Cause - 7 & 0.046 \\
\hline Overall & $\mathbf{0 . 7 5 5}$ \\
\hline
\end{tabular}

Thus if dryness and overheating occurs simultaneously the probability of structural damage of the tank will be $0.925 \times 0.755=0.693$, since dryness and overheating are two independent works.
In short the overall probabilities of all the hazardous circumstances can be summarized as -

\begin{tabular}{|c|c|}
\hline Hazardous Situation & Probability \\
\hline Overflow of the tank & 0.925 \\
\hline Dryness of the tank & 0.925 \\
\hline Overheating of the tank water & 0.755 \\
\hline Cooling of the tank water & 0.755 \\
\hline $\begin{array}{c}\text { Structural damage of the tank due to } \\
\text { simultaneous drying and overheating }\end{array}$ & 0.693 \\
\hline
\end{tabular}

It is noteworthy that the temperature indicator is more reliable than the level indicator. And thus the probability of hazardous incidents related with temperature measuring is lower. Again, since simultaneous drying of tank and overheating of water is a rare case, so the probability of structural damage is much lower than that of overflow or dryness incident.

Another important observation is that the probability of simultaneous failure of several instruments is lower than the individual one. So, if there is more than one protective technique for a system, the failure of that system is less probable, i.e. the system is more reliable. But that will also cause extra expenditure. So, an optimum way should be find out. It is better to use simple, robust instruments than the sophisticated ones. Interestingly, the failure rate of thermometer is much lower than that of thermocouple [2].

\section{Conclusion}

This article focuses on an alternative approach of estimating risk associated with the process variables than the data driven process. The failure rate of the instruments is used in this method for assessing the failure probability. It can be a good approach for the newly built process plants whose characteristics data are still not in hand for the purpose of assessing the risk. After starting with this approach for the very new plant, the data driven approach can be anticipated after few years when enough process characteristics data will be in hand.

In case of designing risk based multivariable and predictive alarm system [1], this approach can be an initial step. Alarms for the very new plants might be designed by incorporating the risk factor estimated by this method along with the consequence analysis rather than with some approximate values of past data from similar types of plants. Then, after adequate data has been collected, the alarm parameters might be fine tuned with help of the real process data.

Further work can be done by comparing the data driven and instruments' failure rate basis risk estimation method in case of model plants with the help of risk based 
alarms. For getting the complete risk factor, consequence factors are also necessary along with the failure probability that is not included in this study.

\section{Acknowledgement}

We are really grateful to the author of [1]. His guidance and inspirations has made us complete this study.

\section{References}

1. Ahmed, S. (2011), Risks based alarm design - a systems approach, In the proceeding of ADCONIP 2011, Hangzho, P.R. China, May 23-26, 2011

2. Frank P. Lees (1986), Loss Prevention in the Process Industries, Butterworths, London, p. -343.

3. Crowl, D.A. and Louvar. J.F., (2009), Chemical Process Safety - fundamentals with applications, $2^{\text {nd }}$ ed., Prentice Hall PTR, New Jersey, USA

4. Yue Cheng, Iman Izadi, and Tongwen Chen - On optimal alarm filter design. In the proceeding of ADCONIP 2011, Hangzho, P.R. China, May 23-26, 2011.

5. E. Cochran and P. Bullemer, "Abnormal situation management: Not by new technology alone," AICHE Safety Conference, 1996.

6. D. D. Woods, "The alarm problem and directed attention in dynamic fault management," Ergonomics, vol. 23, no. 11, pp. 2371-2393, 1995.

7. D. V. C. Reising, J. L. Downs, and D. Bayn, "IIuman performance models for response to alarm notifications in the process industries: An industrial case study," in Proc. Annual Meeting of the Human Factors and Ergonomics Society, vol. 5, pp. 11891193, New Orleans, LA, Sept. 20-24, 2004.

8. Engineering Equipment and Materials Users' Association (EEMUA), Alarm Systems - A Guide to Design, Management and Procurement, EEMUA Publication 191, Version 2, 2007.

9. R. Brooks, R. Thorpe, and J. Wilson, "A new method for defining and managing process alarms and for correcting process operation when an alarm occurs," Journal of Hazardous Materials, vol. 115, pp. 169-174, 2004.

10. D. V. C. Reising and T. Montgomery, "Achieving effective alarm system performance: Results of ASM consortium benchmarking against the EEMUA guide for alarm systems," Proceedings of the 20th Annual CCPS International Conference, Atlanta, GA, 2005.

11. T. Kohda and W. Cuib, "Risk-based reconfiguration of safety monitoring system using dynamic Bayesian network," Reliability Engineering and System Safety, vol. 92, pp. 1716-1723, 2007.

12. K. Anderson, "A risk-based approach to supporting the operator role in complex monitoring systems," 12th Australian Conference on Safety Critical Systems and Software Conference, Adelaide., vol. 86, 2007.

13. I. Iervolino, M. Giorgio, and G. Manfredi, "Expected loss-based alarm threshold set for earthquake early warning systems," Earthquake Engineering and Structural Dynamics, vol. 36, pp. 1151-1168, 2007.

14. T. Varga, F. Szeifert, and J. Abonyi, "Detection of safe operating regions: A novel dynamic process simulator based predictive alarm management approach," Industrial \& Engineering Chemistry Research, vol. 49, pp. 658-668, 2010.

15. I. S. Kim, M. Modarres, and R. N. M. Hunt, "A model-based approach to on-line process disturbance management: The application," Reliability Engineering and System Safety, vol. 29, pp. 185-239, 1990.

16. B. Roffel and J.E. Rijnsdrop (1982), Process Dynamics, Control and Protection, Ann Arbor Science, Ann Arbor, MI, p. - 381. 